\title{
Bending Soft Block Copolymer Nanostructures by Lithographically Directed Assembly
}

\author{
Gregg M. Wilmes, ${ }^{1,2}$ David A. Durkee, ${ }^{1}$ Nitash P. Balsara*, ${ }^{1,2,3}$ and J. Alexander Liddle* ${ }^{2}$ \\ ${ }^{1}$ Department of Chemical Engineering, University of California, Berkeley, CA 94720 \\ ${ }^{2}$ Materials Sciences and ${ }^{3}$ Energy and Environmental Technologies Divisions, Lawrence \\ Berkeley National Laboratory, Berkeley, CA 94720
}

\section{Supporting Information}

SEM Micrographs of the concentric circle pattern over a range of electron-beam dose. For each sample prepared in this study, electron-beam lithography was performed for each pattern over a range of doses from $600-1200 \mu \mathrm{C} / \mathrm{cm}^{2}$. Below $673 \mu \mathrm{C} / \mathrm{cm}^{2}$, no directed assembly was observed in the patterned regions after processing. At doses at or above $673 \mu \mathrm{C} / \mathrm{cm}^{2}$, assembly could be observed by scanning electron microscopy. Faithful assembly was observed between 824 and $1100 \mu \mathrm{C} / \mathrm{cm}^{2}$, outside of this range various failures in assembly occurred. Micrographs on samples patterned between 673$1200 \mu \mathrm{C} / \mathrm{cm}^{2}$ are shown below.

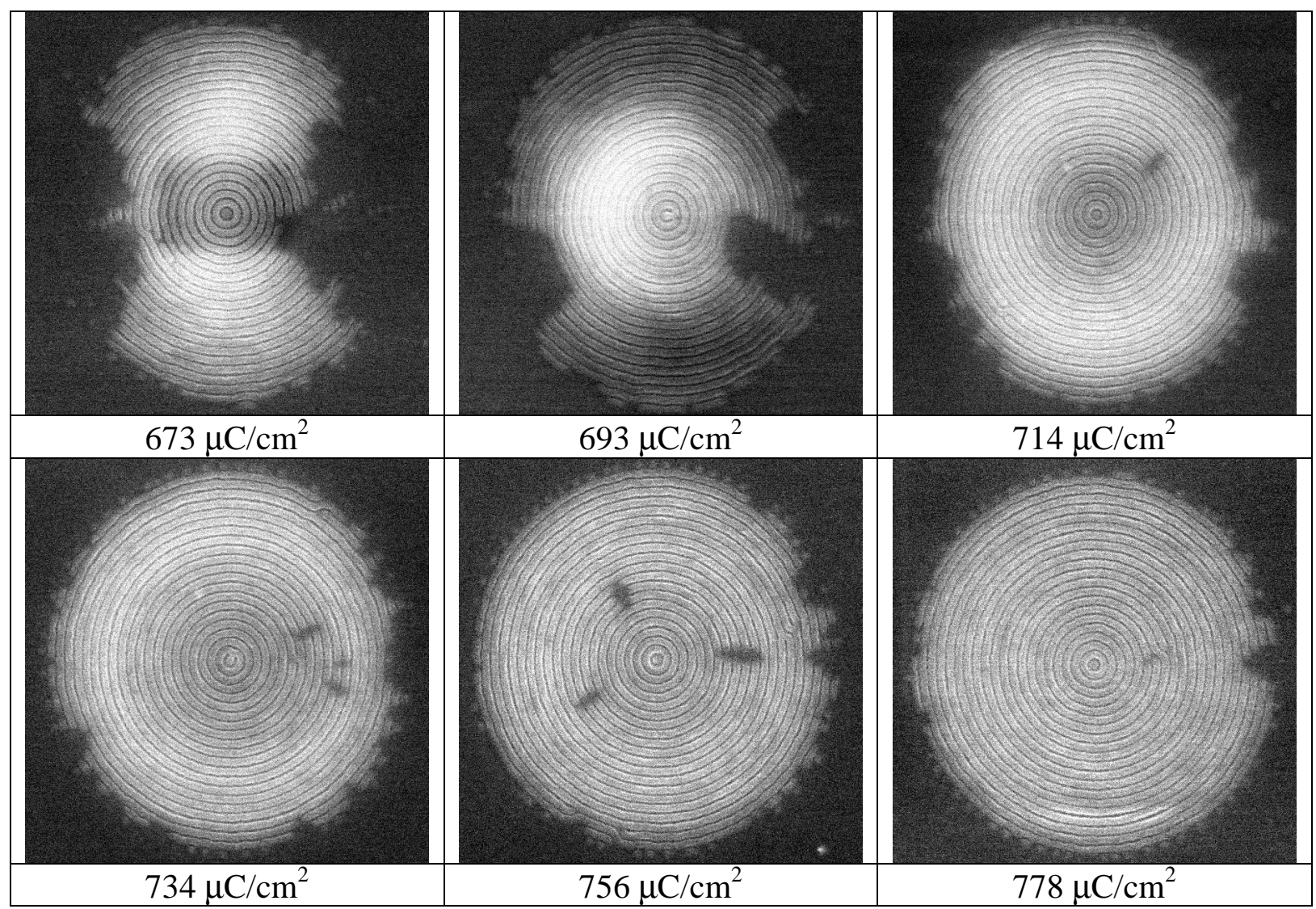




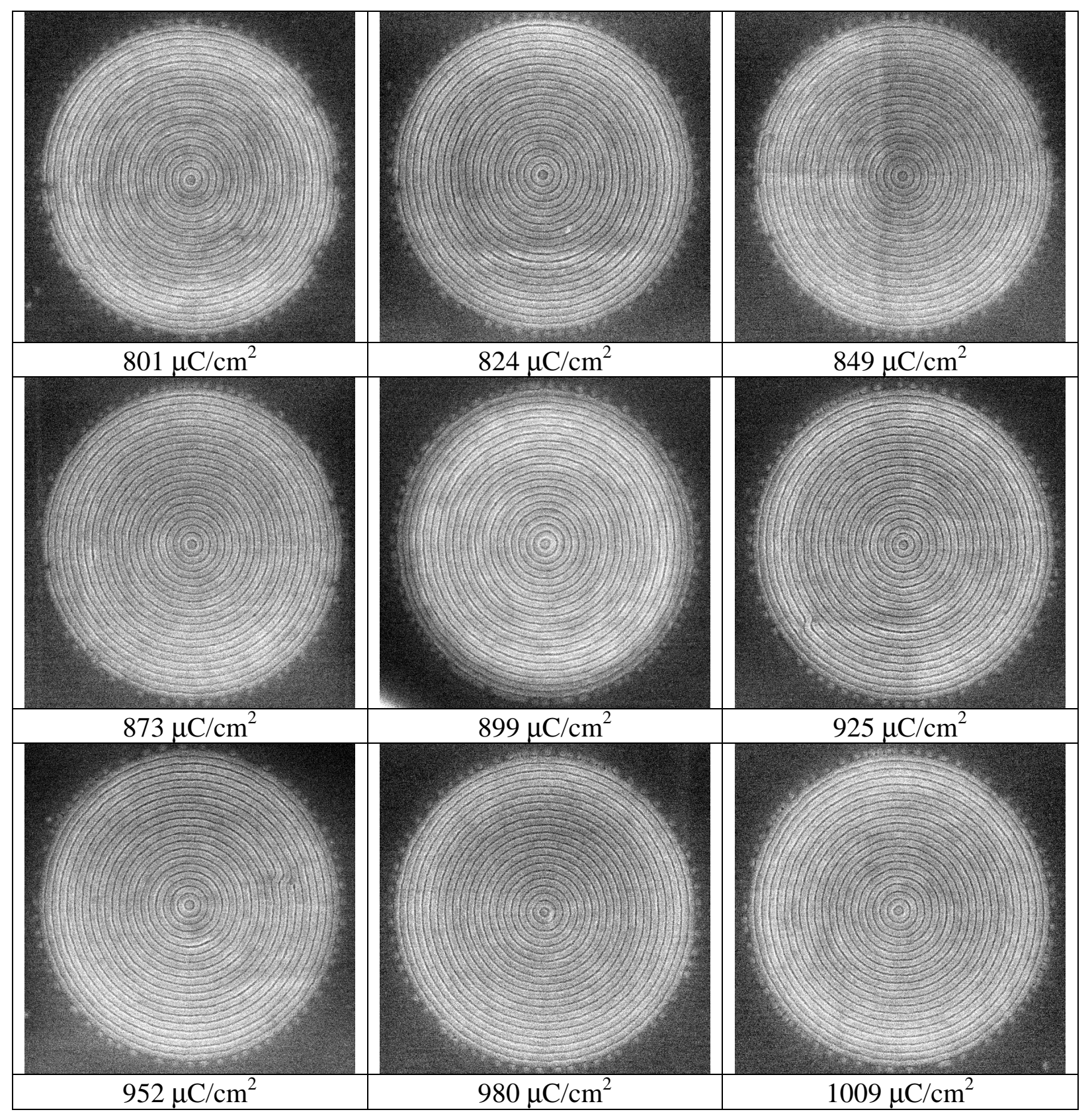




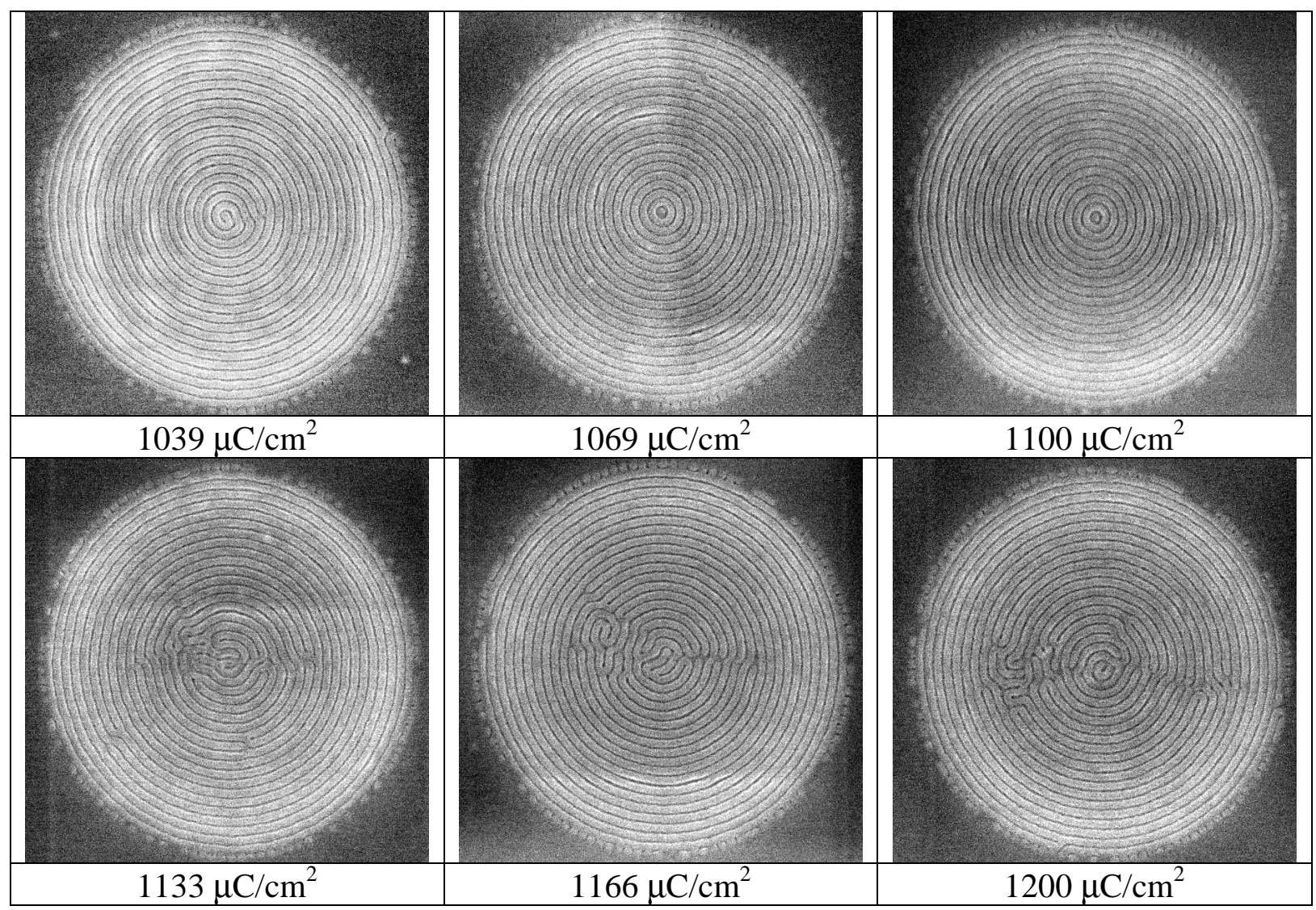

